\title{
Os movimentos sociais e sua relação com a questão da saúde
}

\author{
Lúcia Ribeiro *
}

A temática dos movimentos sociais - tão relevantes hoje para as ciências sociais - tem sido pouco analisada na sua relação com a questão da saúde. $A$ diversidade dos movimentos de saúde e a heterogeneidade de sua base social também dificultam esta análise.

Para compreendê-los propōe-se distinguir duas dimensões: uma estrutural, que se refere às necessidades $e$ caréncias que lhes dão origem $e$ que se observam tanto a nível da situação de saúdel doença quanto dos serviços de saúde; outra cultural, relativa ao processo de conscientização que se dá a partir do reconhecimento destas carências e através do qual vão se explicitando idéias e valores que conformam o significado cultural dos movimentos. No caso dos movimentos de saúde, este parece centrar-se sobre três aspectos: um conceito global de saúde, a igualdade no acesso aos serviços e a exigência de participação.

A relação entre os movimentos sociais e a questão da saúde tem sido pouco explorada, apesar de sua evidente relevância. Há muito poucas análises e pesquisas a respeito e, naturalmente, avançar nesta área é uma aventura ao mesmo tempo fascinan te e perigosa.

Por outro lado, isto se dá em flagrante contraste com o enorme desenvolvimento analítico que vem tendo, nos últimos anos, a temática dos movimentos sociais. É verdade que se trata de um tema recente na literatura sociológica: os primeiros trabalhos referentes aos "movimentos sociais urbanos" começam a surgir, no Brasil, no final dos anos 70 (Silva Telles, 1987); entretanto, esta problemática adquire, rapidamente, notável importância. Isto se deve, basicamente, a dois fatores: por um lado, verifica-se, neste caso, uma relaçāo que se dá freqüentemente entre o processo social, suas oscilações políticas, econômicas e culturais e o fato de privilegiar certos temas nas análises da realidade (Souza, 1987). Se nos anos 60, as ciências sociais estudavam os processos de desenvolvimento e as teorias "desenvolvimentistas" estavam em pleno auge,

* Socióloga e Pesquisadora Visitante do Departamento de Ciências Sociais da Escola Nacional de Saúde Pública, pelo Convênio CNPq/ Fiocruz. no final da década, em face de seu esgotamento e das contradições que se agudizavam, passava-se às teorias da marginalidade e da dependência (Cardoso, 1983); já nos anos 70 a arena da análise se deslocava

Cadernos de Saúde Pública, RJ, 5(3): 264-275, jul/set, 1989 
para a sociedade civil e, no momento atual, os movimentos sociais constituem uma das temáticas mais relevantes, no campo das ciências sociais (Souza, 1987). Além disso, esta relevância deve-se também ao fato de ter suscitado a necessidade de reformular o próprio referencial. Já Moisés, em um dos primeiros trabalhos sobre o tema, adverte: "se o con hecimento for incapaz de refinar os seus instrumentos de análise, para apanhar uma realidade que também é nova e distinta, fracassará nas funçōes a que se auto-atribui" (Moisés 1982:29).

Este esforço se centrou, fundamentalmente, em iluminar uma área anteriormente pouco conhecida e considerada cenário de "contradiçốes secundárias" já que a contradção principal se daria no campo da produção. A esfera da reprodução ganha assim um estatuto teórico e os movimentos que aí se dão passam a ter um lugar antes inexistente "nos referenciais tradicionais voltados para a análise da classe operária na fábrica - no sindicato - no partido" (Silva Telles, 1987:67). Silva Telles identifica, nesta produção, uma verdadeira ruptura com as fomas tradicionais de se pensar a sociedade e a política: se estariam construindo "novos critérios de inteligibilidade do social". É nesse terreno de análise relativamente novo, e já tão relevante para as ciências sociais hoje, que se situa a preocupação específica com a questão da saúde.

Aqui se coloca mais um obstáculo: a enorme diversidade dos movimentos de saúde existentes. $\mathrm{Na}$ realidade, esta diversidade não é mais que um reflexo, nesta área específica, da que se verifica em âmbito mais global. Com efeito, o enorme florescimento destes movimentos, no Brasil, a partir sobretudo dos anos 70 , assume formas as mais diversas, que vão desde associaçōes até movimentos rurais, como os sem-terra ou os movimentos de barragens, passando por movimentos de mulheres, comunidade de base da Igreja Católica, movimentos negros, sindicatos profissionais ou movimentos ecológicos, para citar apenas alguns exemplos.

Mas sua heterogeneidade não se restringe às formas; sua própria base social foge a simplificações esquemáticas, já que muitas delas incluem atores que provêm de classes ou grupos sociais diversificados. Isto se verifica mesmo no interior de movimentos que agrupam basicamente as classes subalternas, já que, ao contrário da situação "clássica" do desenvolvimento capitalista, não se está diante de uma classe operária "stricto sensu", mas de classes populares heterogêneas. (1) Para complicar ainda mais o quadro, os movimentos não são rigidamente estruturados: atravessam ciclos (Frank, 1988) se transformam com as conjunturas sócio-econômicas ou políticas; são, por sua própria natureza, mutáveis. (2) 
Este quadro, amplamente diversificado, caracteriza também os movimentos que dizem respeito à saúde, condicionados pela especificidade do contexto socio-econômico e, de maneira particular, do panorama nosológico no qual se incluem. Aqui, há que distinguir: inicialmente os movimentos que tomam esta questão como seu objetivo exclusivo, enquanto outros a enfocam em conjunção com outros temas.

Existe também diversidade na sua base social; alguns movimentos dizem respeito aos profissionais da área, como, por exemplo, os diversos sindicatos profissionais ou o Movimento Sanitário (3); outros se referem basicamente aos setores populares que, em face das carências que sofrem nesta área, se organizam para lutar por melhores condições de saúde.

Por outro lado, há que distinguir ainda os movimentos que se poderiam denominar "alternativos" centrados nos seus próprios recursos, buscando a nível local solução para suas necessidades, defendendo uma volta às raízes da medicina popular, formando agentes de saúde da comunidade ou ainda descobrindo novas técnicas para lidar com o corpo. As experiências ligadas ao MOPS (Movimento Popular de Saúde) ou al guns projetos ligados à Igreja, por um lado e, por outro, grupos ligados aos Movimentos Feministas, como o SOS Corpo, de Recife, exemplificariam este tipo de movimentos.

A estes se contrapōem movimentos mais "clássicos", baseados em práticas reivindicativas, como as associações de moradores ou os movimentos sindicais, que vêem no Estado o seu principal interlocutor, responsável por garantir a todos os serviços públicos nesta área (4).

Este quadro extremamente heterogêneo e, ao mesmo tempo, relativamente desconhecido e pouco analisado representa um duplo obstáculo: à necessidade de distinções, soma-se também a exigência de descobrir, em função das mesmas, um referencial teórico que permita a compreensão desta realidade.

Este parecia fundamentar-se na explicitação dos mecanismos que possibilitam a construção da identidade social dos movimentos e que se dariam basicamente a nivel de duas dimensões: uma estrutural, outra cultural (Scherer-Warren, 1987).

A dimensão estrutural se refere basicamente à situação de carência e de necessidade que estaria na raiz de qual quer movimento social (Evers et al., 1985).

Esta idéia, na sua generalidade e simplicidade, foi uma das primeiras a ser formulada, na tentativa de explicar a emergência da mobilização social.

Aprofundando esta perspectiva, a partir da problemática urbana, estudiosos europeus, como Castells e Borja, desenvolveram o conceito de "movimentos 
sociais urbanos", entendidos como "sistemas de práticas sociais contraditórias que controvertem a ordem estabelecida a partir das contradições específicas da problemática urbana" (Castells, 1976:3). A primeira destas contradiçōes diz respeito ao aumento crescente das exigências do consumo coletivo, decorrentes do próprio desen volvimento capitalista, contrapostas à incapacidade do sistema para resolvê-las satisfatoriamente; a segunda se refere ao modo individual de apropriação das condições de vida e o modo coletivo de gestão deste processo.

Estas duas contradições determinam a presença necessária ao Estado na gestão dos problemas urbanos; esta intervenção, entretanto, só se realiza dentro da lógica imposta pelas forças sociais existentes: na medida em que o Estado expressa, em última instância, os interesses das classes dominantes, sua presença termina por implicar dominação e integração; é neste contexto que emergem os movimentos sociais urbanos (Castells, 1986). Assim, na gênese destes movimentos, estariam as "novas necessidades" resultantes do desenvolvimento das forças produtivas, contrapostas aos objetivos de uma política que não as prioriza.

Este pensamento teve, inicialmente, uma enorme influência nos estudos realizados no Brasil. Entretanto, embora se mantivesse a mesma perspectiva teórica, baseada na denominada "questão urbana", não foi difícil perceber que, no contexto do capitalismo periférico, esta adquiria uma intensificação e uma gravidade impensáveis na realidade do capitalismo avançado, que havia servido de pano de fundo para a reflexão européia. No Brasil, o modo de acumulaçāo de "base pobre" implicou a ativação de mecanismos de superexploração da força de trabalho, e na minimização da participaçāo privada e, particularmente, do Estado, nos custos de reprodução desta força de trabalho (Moisés, 1985). Kowarick também acentua esta dimensão, ao caracterizar, por um lado, o processo de pauperização - relativa ou absoluta - resultante das condições de exploração da força de trabalho e, por outro, 0 que denomina espoliação urbana: "somatória de extorçōes que se opera através da inexistência ou precariedade de serviços de consumo coletivo que se apresentam como socialmente necessários em relação aos níveis de subsistência das classes trabalhadoras e que agudizam ainda mais a dilapidação que se realiza no âmbito das relações de trabalho"' (Kowarick, 1985:30).

Estas formulações permitiram uma compreensão mais clara dos processos que estariam na base dos movimentos sociais urbanos no Brasil ( $\mathrm{J}$ acobi e Nunes, 1983).

Entretanto, a evolução das análises veio mostrar que nāo bastava "adaptar" o pensamento europeu às

Cadernos de Saúde Pública, RJ, 5(3): 264-275, jul/set, 1989 
especificidades do capitalismo periférico. Novos problemas se colocavam: alguns autores questionavam o que consideravam uma "transposição acrítica" (Machado e Ziccardi, 1979). Impunha-se a revisão do próprio instrumental de análise, no sentido de averiguar até que ponto poderia dar conta da complexidade das novas realidades no Brasil.

Outros autores questionam o caráter da gestāo estatal, que não seria o mesmo, no capitalismo avançado ou numa realidade social como a brasileira (Jacobi, 1985; Machado e Ziccardi, 1979).

Finalmente, tem havido também discussões sobre o risco de economicismo, (Moisés, 1985) inerente a uma análise que faz derivar do âmbito macroestrutural mobilizações concretas (Jacobi, 1985). A ênfase nas condiçōes materiais objetivas poderia obscurecer a importância de fatores socio-culturais e políticos na compreensão da emergência das mobilizaçōes. Levada às últimas consequêencias, esta perspectiva poderia "desembocar numa linearidade teórica que equaciona o acirramento das contradições com o aprofundamento dos conflitos sociais" (Kowarick, 1986).

O processo, certamente, é bem mais complexo. A simples situação de privação econômica não é suficiente para explicar a mobilização social, nem pode considerar-se sua única causa (Kämer, 1987). Nấo há dúvida que $o$ grau de carências em que vive a maior parte da população é um ponto de partida imprescindivel; isto é ainda mais verdadeiro num país onde os níveis mínimos de subsistência precisam ainda ser conquistados para grande parte da população. Mas é justamente a gravidade desta situaçáo que leva à comprovação de que "a miséria não leva necessariamente à mobilização; as interpretações mecanicistas de que as mobilizações populares são consequêencia da espoliação urbana esbarram nos dados da própria realidade brasileira. Em um país onde $61,2 \%$ da população economicamente ativa não chegam a receber nem dois salários mínimos mensais e está abaixo do que é considerado a "linha da pobreza", se esta hipótese fosse verdadeira, já teríamos há muito um governo popularrevolucionário no Brasil. (Caccia-Bava, 1987).

A mobilização só se dá quando há uma tomada de consciência coletiva da situação de privação levando à organização do grupo para reivindicar seus direitos; entre estes se inclui justamente, como ponto de partida, "o simples reconhecimento de sua situação de exclusão social e a possibilidade de lutar por melhores condições de sobrevivência" (Moisés, 1985:26).

Neste processo de reconhecimento e defesa dos próprios direitos o movimento vai se constituindo; isto implica, simultaneamente, a formulação de uma "visão de mundo": orientaçōes, princípios e valores que con-

Cadernos de Saúde Pública, RJ, 5(3): 264-275, jul/set, 1989 
ferem ao movimento um significado cultural.E é na conjunção destas duas dimensões - estrutural e cultural - que se constrói sua identidade (Scherer-Warren, 1987:40).

Vários autores, trabalhando numa linha que, segundo Kowarick, constitui uma "rica veia interpretativa", vêm enfatizando o significado cultural dos movimentos sociais (Kowarick, 1986).

Trata-se de ir descobrindo os resultados de um processo que não corresponde a nenhum projeto preconcebido, mas emerge da prática cotidiana dos movimentos. É a partir do seu trabalho de base, e da discussão localizada sobre os problemas do dia-a-dia, que milhares de grupos em centenas de cidades estariam forjando um novo tipo de discurso: valores, aspirações, utopias (Kowarick, 1986).

Partindo do reconhecimento das formas de opressão e de dominação, esta cultura que se vai construindo traz uma dimensão crítica e basicamente anti-autoritária. Seus elementos ainda que fragmentários e dispersos, podem ser reconhecidos através da diversidade das práticas dos movimentos; entre eles, os valores centrais parecem ser os princípios da igualdade e da democracia (Barreira, 1987), implicando uma exigência de participação (Jacobi e Nunes, 1983), entendida como presença ativa na tomada de decisōes (Evers et al., 1985) ou mesmo como tentativa de autogestão das bases, apontando para caminhos de auto-regulação da sociedade (Krischke, 1987).

Scherer-Warren sistematiza melhor estes diversos aspectos, agrupando-os em tomo de três eixos:

1) reação às formas autoritárias, propondo democracia (direta, de base ou representativa);

2) reação às formas centralizadoras do poder, defendendo autonomias locais e sistemas de autogestão;

3) reação ao caráter excludente no modelo econômico, encaminhando novas formas de vida mais comunitária (Scherer-Warren, 1987).

Nesta busca de valores próprios, vai-se construindo uma identidade que significa afirmar-se como sujeitos de sua própria história. Isto implica uma autopercepção realista de suas próprias características, potenciais e limitaçōes, superando falsas identidades outorgadas de fora.

Naturalmente, o discurso que resulta deste processo é ainda fragmentário, desorganizado e muitas vezes contraditório. Corresponde, de certo modo, à própria fragilidade e inorganicidade dos movimentos. Por suas práticas localizadas e referidas a reivindicações específicas, os movimentos sociais não são ca- 
pazes de articular um projeto global e acabado para a sociedade na qual se inscrevem (Caccia-Bava, 1987) e menos ainda de formular propostas políticas sistematicamente estruturadas e imediatamente aplicáveis. Neste sentido, é possível afirmar que seu potencial transformador assume muito mais uma dimensão sociocultural do que estritamente política (Evers, 1984), cabendo a esta última, tradicionalmente, os partidos. Os movimentos não pretendem substituí-los: o principio de autonomia, em relação às orientações políticopartidárias, se coloca reiteradamente em seu discurso, como um dos seus fundamentos - mesmo que, na prática, a relação seja bem mais complexa e não isenta de ambigüidades.

A esta desarticulação dos movimentos, haveria que acrescentar um outro fator, para compreender a "desorganização" do seu discurso: os movimentos sociais estão inseridos em um contexto socio-político no qual prevalecem os valores dominantes; estes exercem uma pressão permanente sobre os elementos emergentes, que estariam se dando na "franja contestadora da sociedade". Enquanto os primeiros constituiriam sua face visível, estruturada e dominante, os últimos seriam a sua "face oculta" (Evers, 1984). Esta aparece, portanto, permeada de contradições e freqüentemente distorcida pelos valores dominantes.

Apesar de tudo isso, os elementos culturais, forjados nos movimentos, parecem trazer em si um projeto emancipatório (Evers, 1984). Ainda que não constituam um projeto político acabado, abrem pistas para uma transformação social mais global.

Estas pistas é que necessitam ser descobertas e reconhecidas, através da pesquisa cuidadosa e paciente. Tal esforço, evidentemente, está sempre sujeito a riscos, enganos ou superestimações, e só uma visão permanentemente crítica, despojando-se de preconceitos e de avaliações ideológicas preestabelecidas poderá evitá-1os. Também Souza alerta para este risco: "o imaginário social, se não estiver rigorosamente ancorado nas tramas das contradiçōes reais, se confunde facilmente com a imaginação ou os desejos dos analistas, ou surge em alguns como compensação de suas esperanças frustradas em tempos anteriores de militância política que os fizeram abortar' (Souza, 1987). Sugere então que a busca de novas abordagens não esqueça elementos significativos acumulados nas análises anteriores.

Isto implica, concretamente, situar o discurso que vem sendo formulado pelos movimentos sociais no contexto social que lhes deu origem, levando em conta sua permanente interação com outros autores sociais.

Já nos referimos à relação com os partidos políticos; é indispensável analisar também a relação com o Estado, as classes, a Igreja, os profissionais e técni- 
cos. São estas mediações - cuja análise será desenvolvida em trabalhos posteriores - que permitem compreender o significado cultural dos movimentos sociais.

\section{OS MOVIMENTOS DE SAÚDE}

A reflexão desenvolvida até aqui pode fornecer elementos para captar o que se passa, de maneira mais específica, nos movimentos sociais que dizem respeito à área da saúde.

$\mathrm{O}$ que se pretende é levantar algumas questōes pertinentes para a sua compreensão. Longe de afirmar certezas definitivas sobre uma temática bastante controvertida, busca-se simplesmente abrir a discussão e levantar algumas pistas para futuros aprofundamentos.

Retomando a linha anteriormente explicitada, é possível perceber, também para os movimentos de saúde, as duas dimensões básicas, na construção de sua identidade social.

A dimensão estrutural diz respeito às carências que se observam na área da saúde, e que se centram na questão dos serviços de saúde, embora não se limitem a estes.

As contradições que resultam de um processo de desenvolvimento desigual, característico do modelo adotado pelo país, reflete-se também na situação de saúde: às doenças típicas de zonas pouco desenvolvidas se somam as que são prevalentes em países industrializados.

Face a este quadro, o sistema oficial de serviços de saúde se revela ainda inadequado, tanto do ponto de vista quantitativo como qualificativo; é verdade que estes serviços se ampliaram significativamente nos últimos anos e nisto o Estado jogou um papel central; isto não significa, entretanto, que as verdadeiras necessidades da população tenham sido satisfeitas: não apenas esta expansão está longe de chegar a uma total cobertura, como, por outro lado, a diferenciação da prática médica - que se expressa fundamentalmente no seu caráter privado ou público - é uma realidade, condicionada essencialmente pela situação de classe dos diferentes grupos sociais.

Entretanto, aqui também não se pode derivar mecanicamente as mobilizações sociais da existência das carências nesta área. Por maiores que sejam estas, só se transformam em motor das mobilizaçoos na medida em que são vivenciadas e reconhecidas como tais: é este processo de tomada de consciência que leva à reivindicação dos próprios direitos. $\mathrm{E}$, neste processo, vão se explicitanto valores, que conformam à di- 
mensão cultural dos movimentos e vāo construindo, no campo da saúde, um discurso próprio.

Estes valores dizem respeito, basicamente, a três aspectos:

1) ao conceito global de saúde - $\mathrm{Na}$ medida em que os movimentos reconhecem, na saúde, uma dimensão coletiva - e não apenas um problema pessoal pelo qual cada um é individualmente responsável - se explicita, também, seu condicionamento social: a situação de saúde depende diretamente das condições de vida, e não se resolve independentemente destas; 0 direito à saúde implica trabalho em condiçôes dignas, alimentaçâo para todos, moradia higiênica, educação e informação, qualidade adequada do meio ambiente, transporte acessível e seguro, descanso, lazer e segurança (Costa, 1986);

2) à igualdade no acesso aos serviços de saúde - Na reivindicação de "saúde para todos" se inclui o direito a serviços de saúde universalmente acessíveis e gratuitos, o que implica a responsabilidade do Estado;

3) à exigência de participação - A necessidade de se assumir enquanto sujeito e de falar em primeira pessoa se impõe, já que a própria percepção da situação e de suas causas encontra seus parâmetros na posição que os setores sociais ocupam na estrutura social. Cada setor tem uma maneira própria de pensar sua inserção na sociedade, tomando como ponto de partida sua situação de vida. Esta interpretação diversa da realidade está na base da exigência de fazer ouvir sua voz e de participar efetivamente para poder solucionar seus problemas. Tal percepção da participação, como um valor, se origina e ao mesmo tempo se expressa na prática dos movimentos.

No caso da saúde, assumir-se como sujeitos de sua própria vida - "ser dono de sua saúde e participante de sua cura" (Carvalho, 1986) implica, para os movimentos, participar especificamente, no planejamento, gestão e avaliação de ações de saúde, especialmente a nível local.

Naturalmente, esta sistematização analítica nem sempre se dá na prática dos movimentos concretos. Aqui também a distinção tem sobretudo um valor heurístico, formulando hipóteses do que poderiam ser os eixos sobre os quais se constrói seu discurso.

Tampouco trata-se de um discurso exclusivo ou ori ginal: os valores que vão configurando o perfil ideológico dos movimentos não brotaram espont aneamente 
de zero, mas se inscrevem num processo conjunto, no qual a atuação de diversas mediaçōes é fundamental.

Entre estas, cabe destacar a relaçăo com os técnicos e profissionais da saúde - sobretudo no caso dos movimentos de base popular; a relação com os partidos e grupos políticos; a relação com as Igrejas, e de modo especial a Igreja católica; e a própria relação com o Estado, marcada por ambigüidades e contradiçōes, mas central na compreensão do processo.

Só a análise conjunta destas múltiplas relaçōes permite apreender, na sua globalidade, o processo pelo qual os movimentos vão construindo sua identidade.

Por outro lado, ao tratar de dar respostas aos problemas concretos que se colocam, este processo se particulariza e se especifica, no caso de cada movimento. Sua análise exige, por isto mesmo, pesquisas cuidadosas e pormenorizadas, que, em grande parte, estão ainda por se fazer.

A imensidade da tarefa, entretanto, não deve desanimar; pode ser vista, ao contrário, como um desafio: sem o (re) conhecimento das pistas abertas pelos movimentos sociais, será impossível pensar as possibilidades de uma verdadeira democratização da saúde.

The theme of social movements - so relevant today to social sciences - has been scarcely analysed in its relationship to the health conditions. The diversity of health movements and the heterogenity of its social basis present difficulties for this analysis.

To understand them, it is proposed to distinguish two dimensions: a structural one, which refers to needs and gaps which give origin to this diversity that can be observed both at the level of the health/illness situation and the level of health services; and a cultural one, related to the process of "conscientization" born from the recognition of these gaps and through which ideas and values become compatible with the cultural meaning of these movements. In the case of health movements, this seems to be centered upon three aspects: a global concept of health, equality in the access to health services and claim for participation.

\section{NOTAS}

1) A noçäo de "classes populares", embora necessite ser teoricamente aprofundada, tem um grande valor heurístico, ao apontar para a complexidade dos setores subalternos, socialmente heterogêneos; por isto mesmo, vem sendo crescentemente utilizada na literatura socioló 
gica, sobretudo por autores que estudam os movimentos sociais. (ver, por exemplo, Lúcio Kowarick, José Alvaro Moisés e Luiz Alberto G. de Souza, cujas obras constam da presente bibliografia).

2) O título de uma das mais recentes análises sobre o tema é sugestivo: "Caminhos e descaminhos dos movimentos sociais no campo" de Cândido Grzybowski - Ed. Vozes - Petrópolis, 1987.

3) Ver a análise de BOSCHI (1987) sobre o movimento dos médicos, no capítulo " $\mathrm{Um}$ ator organizado: A ssociaçōes profissionais e sindicalismo de classe média" e a dissertaçāo de mestrado de MORAES, Sarah Escorel de - Reviravolta na Saúde - Origem $e$ articulação do Movimento Sanitário. Escola Nacional de Saúde Pública FIOCRUZ - Rio de Janeiro, 1987.

4) As experiências participativas ligadas ao próprio Governo Municipal ou Estadual, como as citadas por LEITÃO, Célia, "Participação popular nos programas de saúde" in A saúde em estado de choque - (op. cit.) representam também novos espaços de participação popular, embora talvez não possam ser consideradas estritamente como movimentos sociais.

\section{REFERÊNCIAS BIBLIOGRÁFICAS}

BARR EIRA, Irlys A lencar F. - Movimentos urbanos e política: questóes da teoria e da prática. Trabalho apresentado ao XI Encontro Anual da ANPOCS - Mimeo - Águas de São Pedro, outubro de 1987.

BORJA, Jordi - Movimientos sociales urbanos Siap - Buenos Aires, 1975.

BOSCHI, Renato Raul - $A$ arte da associação Co-ediçāo Vértice e IUPERJ - São Paulo/Rio de Janeiro, 1937.

CACCIA-BAVA, Silvio - As lutas pela terra em São Paulo - Ocupaçóes da ANPOCS - Mimeo - Aguas de São Pedro, outubro de 1987.

CARDOSO, Ruth C. - "Movimentos sociais urbanos: balanço critico" in SORJ, Bernardo e ALMEIDA, Maria Hermínia T. (org.) - Sociedade e política no Brasil pós-64 - 2: ediçăo, Brasiliense - São P aulo, 1984.

CARVALHO, Josiane M. P. Lechat - "Entre a zona canavieira e o sertão de Pernambuco: um projeto de educação e saúde", in MINAYO, M. Cecilia de Souza (org.) - A saúde em estado de choque - co-edição Espaço e Tempo e FASE Rio de Janeiro, 1986.

CASTELLS, Manuel - Movimientos sociales urbanos - 2: ediçăo. Siglo Veintiuno - Buenos Aires, 1976. - Cidade, democracia e socialismo Paz e Terra - Rio de Janeiro, 1980.

COSTA, Nilson do Rosário - "Saúde igual direito à vida" in MINA YO, M. Cecília de Souza (org.) - A saúde em estado de choque - Co-edição Espaço e Tempo e FASE - Rio de Janeiro, 1986.

Cadernos de Saúde Pública, RJ, 5(3): 264-275, jul/set, 1989 
EVERS, Tilman - "Identidade, a face oculta dos novos movimentos sociais" in: Novos Estudos CEBRAP, vol. 2 - 4 - São Paulo, Abril, 1984.

_ et alii - "Movimentos de bairro e Estado: Lutas na esfera da reproduçāo na América Latina" in MOISÉS, José Alvaro et alii - Cidade, povo e poder - 2: edição - Paz e Terra, Rio de Janeiro, 1985.

FRANK, André Gunder e FUENTES, Marta - "Nine thesis on social movements" in IFDA Dossier 63 - International Foundation for development alternatives - janffev., 1988. Nyon Suíça.

JACOBI, Pedro Roberto - Políticas públicas de saneamento básico $\epsilon$ saúde e reivindicaçōes sociais no Município de Sāo Paulo - 1974/1984 - Dissertação de Doutorado em Sociologia Mimeo, São Paulo, 1985.

- e NUNES, Edson - "Movimentos sociais urbanos na década de 80: mudanças na teoria e na prática" in Espaço e Debates - n: 10 - NERU - Săo Paulo, 1983.

KÄRNER, Hartmut - "Movimentos sociais: revolução no cotidiano" in SCHERER-WARREN, Ilse e KRISCHKE, Paulo J. (org.) - Uma revoluçāo no cotidiano? Os novos movimentos sociais na América Latina - Brasiliense - São Paulo, 1987.

KOWARICK, Lúcio - "O preço do progresso: crescimento econômico, pauperização e espoliação urbana" in MOISÉS, J. A. et alii. - Cidade, povo e poder - 2: ediçāo - Paz e Terra, Rio de Janeiro, 1985.

- Movimentos urbanos no Brasil contemporâneo: uma análise da literatura. Mimeo - Sāo Paulo, 1986.

KRISCHKE, P aulo J. - "Movimentos sociais e transição política: contribuiçōes da democracia de base" in Uma revolução no cotidiano? ... op. cit.

MACHADO DA SILVA, Luiz Antonio e ZICCARDI, Alicia - Notas para uma discussāo sobre os movimentos sociais urbanos IUPERJ - Mimeo - Rio de Janeiro, 1979.

MOISES, José Alvaro. "O Estado, as contradições urbanas e os movimentos sociais", in MOISÉS, J. A. et alii - Cidade, povo $e$ poder, 2: edição, Paz e Terra. Rio de Janeiro, 1985.

SCHERER-WARREN, Mse - "O caráter dos novos movimentos sociais" in Uma revoluçäo no cotidiano? ... Op. cit.

SOUZA, Luiz Alberto Gómez de - Classes populares e Igreja nos caminhos da história - Petrópolis, 1982.

- Resenha temática: movimentos sociais no Brasil Centro João XXIII - Mimeo - Rio de Janeiro, 1987.

TELLES, Vera da Silva - "Movimentos Sociais: reflexöes sobre a experiência dos anos $70^{\prime \prime}$ in Uma revoluçāo no cotidiano? ... - Op. cit.

VIOLA, Eduardo e MAINWARING, Scott - "Novos movimentos sociais, cultura política e democracia: Brasil e Argentina" in Uma revolução no cotidiano? ... Op. cit. 